\title{
Técnicas de Limpeza de Perfis de Retardos de Potência e sua Influência no Espalhamento de Retardo em Canal UWB
}

\author{
Bianca S. Marinho e Leni J. de Matos
}

\begin{abstract}
Resumo-A limpeza de ruído de perfis de retardo de potência é realizada através de três diferentes técnicas. Tais perfis são obtidos por processamento off-line de dados relativos a medidas em um ambiente interno, em um canal UWB. Para cada técnica de limpeza aplicada, a dispersão temporal do sinal é obtida através da determinação do espalhamento de retardo médio no ambiente, e comparações desses valores são realizadas de forma a se concluir sobre a influência de tais técnicas nos mesmos.
\end{abstract}

Palavras-Chave-limpeza de ruído, espalhamento de retardo, UWB.

Abstract-Power delay profiles de-noising is carried out through three different techniques. Such profiles are obtained from the off-line processing of data related to measurements in an indoor environment, in a UWB channel. For each applied de-noising technique, the temporal dispersion of the signal is obtained through the calculus of mean delay spread in the environment, and comparisons of these values are made in order to conclude about the influence of such techniques in them.

Keywords-de-noising, delay spread, UWB.

\section{INTRODUÇÃO}

A tecnologia UWB (Ultra Wide-Band) permite taxas de transferência que podem variar de valores baixos, como 100 kbps para um mouse sem fio, a valores bastante elevados, como $100 \mathrm{Mbps}$, para o download de imagens e compartilhamento de arquivos de multimídia. O estabelecimento dessas taxas de transmissão, permitidas no canal UWB, é possível através do conhecimento do parâmetro de dispersão temporal do canal, conhecido como espalhamento de retardo $\left(\sigma_{T}\right)$ [1]. O canal rádio é o principal responsável pelas limitações na comunicação. Além do ruído do receptor, o ruído introduzido pelo canal, no sinal em propagação, também contribui para a deformação do sinal recebido. Assim, de posse dos PDPs (Perfis de Retardo de Potência), tal ruído indesejado deve ser minimizado, através de uma técnica de limpeza apropriada, de forma que se obtenham valores mais confiáveis para $\left(\sigma_{T}\right)$.

Dentre as técnicas de limpeza existentes, o que se propõe neste artigo é aplicar três delas [2-4] num mesmo conjunto de PDPs, obtidos em um ambiente interno para um canal UWB, e concluir sobre a influência das mesmas no $\left(\sigma_{T}\right)$. Este artigo está dividido da seguinte forma: a Seção II apresenta as técnicas de limpeza de ruído empregadas, a Seção III, fornece dados do sistema de sondagem empregado nas medições e a Seção IV, dá as conclusões e os passos para a continuidade do trabalho.

Bianca Santos Marinho e Leni Joaquim de Matos, Depto de Engenharia de Telecomunicações, Escola de Engenharia, Universidade Federal Fluminense, Niterói, RJ, E-mails: bianca.s.marinho@gmail.com / lenijm@ig.com.br

\section{TÉCNICAS DE LIMPEZA DE RUÍDO}

\section{A. Técnica com emprego de CFAR}

Nesta técnica uma CFAR (Constant False Alarm Probability) é empregada [2], independente da relação SNR (sinal/ruído). O valor adotado foi igual a $5 \cdot 10^{-6}$, equivalendo a um falso alarme a cada 78 perfis medidos. O limiar de ruído (LR), em dB, e variável perfil a perfil, é obtido conforme Sousa [2]:

$$
\text { LR = MP - NRT- pmv + CFAR (1) }
$$

onde MP é a mediana do perfil, NRT é o desvio padrão do ruído térmico, relativo à mediana, e pmv é a probabilidade de multipercursos válidos no perfil, adotada igual a $14 \%$, visto que os perfis medidos apresentam, em geral, fortes multipercursos até $300 \mathrm{~ns}$. Todos os valores se acham em dB. A Figura 1 exemplifica um perfil ruidoso obtido, onde os pontos representam os picos dos multipercursos válidos, após a limpeza do perfil, a serem usados no cálculo de $\left(\sigma_{T}\right)$.

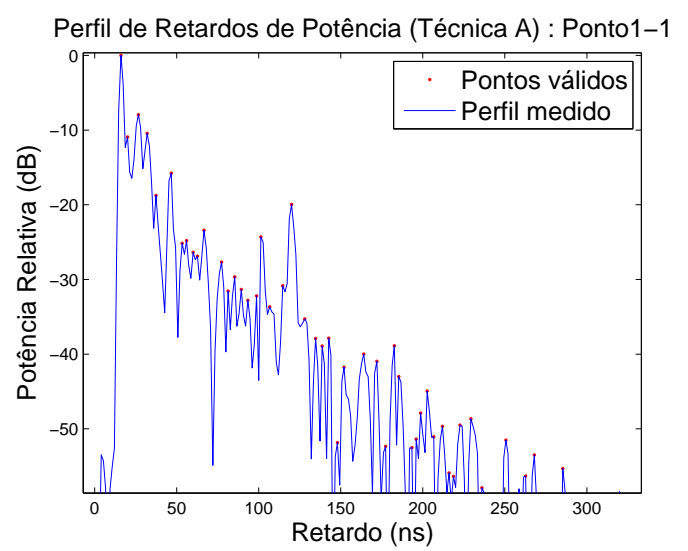

Fig. 1. Exemplo de PDP limpo com a técnica A

\section{B. Técnica CLEAN}

O algoritmo desta técnica encontra o sinal mais forte através da correlação do sinal recebido com uma forma de onda padrão de referência e identificando o maior pico nesta correlação. Apenas as correlações acima de $80 \%$ foram consideradas para se concluir sobre um multipercurso válido [3]. A medida dessa referência foi realizada em visada, num campo aberto, praticamente sem espalhadores, com antenas transmissora e receptora distantes de 1 metro, de forma a garantir apenas a 
recepção do raio direto. A amostra que gerou este pico de correlação é subtraída do sinal total, e o pulso é novamente correlacionado com o sinal "limpo", resultante desta subtração. Este procedimento é repetido, iterativamente, até que o nível de sinal no perfil que está sendo limpo fique abaixo de um determinado limiar. O fluxograma é detalhadamente explicado em Souza [3]. Na Figura 2 está um exemplo do mesmo perfil ruidoso da Figura 1, mas que foi limpo pela técnica CLEAN. Nele, os pontos representam os picos dos multipercursos válidos.

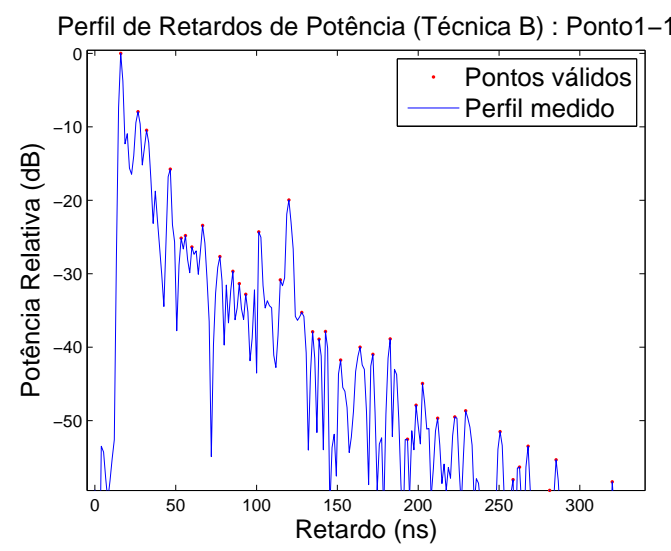

Fig. 2. Exemplo de PDP limpo com a Técnica Clean

\section{Técnica WDEN (Wavelet de-noising)}

Esta técnica trabalha com a supressão de ruído (denoising) baseada na decomposição por wavelets. Assim, essa decomposição fornece uma limpeza dos perfis de retardo de potência. Segundo Dias [4], melhores resultados são obtidos quando se opera, independentemente, sobre as componentes real e imaginária do sinal medido, em vez de seu módulo. O software MATLAB já trabalha diretamente com WDEN, no sinal em que se deseja efetuar a limpeza de ruído, e as funções-base aqui empregadas, assim como em [4], foram do tipo sym8 (symlet8). Na Figura 3 tem-se um exemplo do perfil ruidoso, onde os pontos representam os picos dos multipercursos válidos, após a limpeza.

\section{TABELAS E RESULTADOS}

A tabela I apresenta os dados referentes ao sistema de sondagem do canal UWB medido, em ambiente interno, empregando a varredura de freqüência [4]. Na Tabela II, os valores de $\sigma_{T}$ obtidos após o processamento dos dados, empregando as três técnicas citadas, são fornecidos.

TABELA I

DAdos DA SONDAGEM NO CANAL

\begin{tabular}{|l||c|}
\hline Banda utilizada, em MHZ & 750 \\
\hline Número de pontos medidos, em frequência & 1601 \\
\hline Resolução na frequência, em MHz & 0,46875 \\
\hline Retardo Máximo, em ns & 2133,33 \\
\hline Resolução no domínio do tempo, em ns & 1,33333 \\
\hline
\end{tabular}

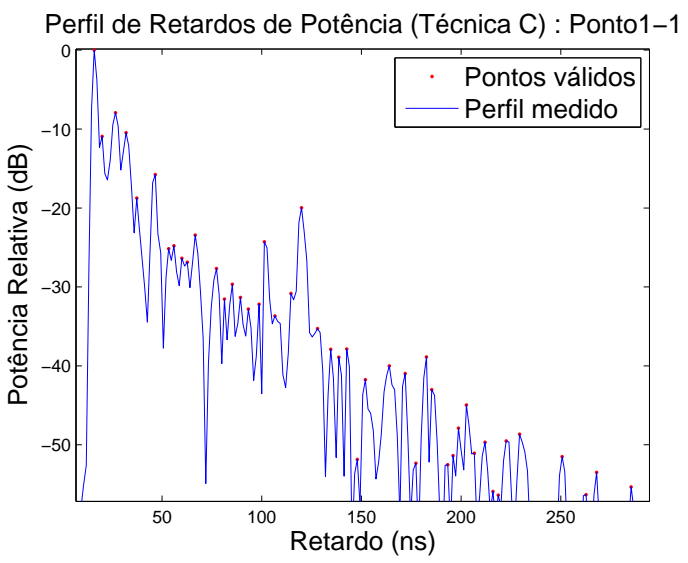

Fig. 3. Exemplo de PDP limpo com as wavelets

TABELA II

COMPARAÇÃO DOS RESULTADOS

\begin{tabular}{|l||c|c|l|}
\hline Técnica & $\sigma_{T}$ médio & Desvio Padrão & $\begin{array}{l}\% \text { de variação } \\
\text { da média }\end{array}$ \\
\hline \hline $\mathrm{A}$ & 12,0942 & 1,3563 & $8,91 \%$ \\
\hline $\mathrm{B}$ & 13,3588 & 1,9960 & $6,69 \%$ \\
\hline $\mathrm{C}$ & 12,7807 & 1,7673 & $7,23 \%$ \\
\hline
\end{tabular}

\section{CONCLUSÕES}

Utilizando dados disponibilizados de canais UWB, em um ambiente interno da Escola de Engenharia da UFF, três técnicas de limpeza de PDPs foram empregadas e o espalhamento de retardo foi calculado em cada caso. Os valores de $\sigma_{T}$ obtidos no ambiente são muito próximos, indicando que as três técnicas se equivalem no canal aplicado. Na continuidade deste trabalho, outros ambientes internos estão sendo analisados de forma a se concluir sobre o uso indistinto de qualquer uma das técnicas em canais internos UWB.

\section{AGRADECIMENTOS}

À Universidade Federal Fluminense, pela bolsa de iniciação científica concedida, via PIBIC.

\section{REFERÊNCIAS}

[1] PARSONS, D. The Mobile Radio Propagation Channel. 2.ed., New York: John Wiley e Sons, 1992. 418p.

[2] SOUSA, E. S.; JOVANOVIÉ, V. M.; DAIGNEAUlT, C. Delay Spread Measurements for the Digital Cellular Channel in Toronto.IEEE Transactions on Vehicular Technology, v.43, n.04, p. 837-847, Novembro 1994.

[3] SOUZA, C. F. Análise da dispersão temporal de canais de banda ultralarga $(U W B)$ através de medidas realizadas em ambientes internos e externos, 251 f. Dissertação de Mestrado - UFF-RJ, Julho 2006.

[4] DIAS, M.H.C. and Siqueira, G.L. On the Use of Wavelet-Based Denoising to Improve Power Delay Profile Estimates from $1.8 \mathrm{GHz} \mathrm{In}$ door Wideband Measurements. Wireless Personal Comm., Springer 2005, pp.153-175. 